\title{
Invasive pneumococcal disease in a third level pediatric hospital in Mexico City: epidemiology and mortality risk factors
}

\author{
Demóstenes Gómez-Barreto, MD, (1) Luz Elena Espinosa-Monteros, DSc, (2) Claudia López-Enríquez, MD, ${ }^{(3)}$ \\ Verónica Jiménez-Rojas, MSc, ${ }^{(1)}$ Romeo Rodríguez-Suárez, MD.(4)
}

\begin{abstract}
Gómez-Barreto D, Espinosa-Monteros LE, López-Enríquez C, Jiménez-Rojas V, Rodríguez-Suárez R. Invasive pneumococcal disease in a third level pediatric hospital in Mexico City: epidemiology and mortality risk factors. Salud Publica Mex 2010;52:391-397.
\end{abstract}

\begin{abstract}
Objective. To assess the epidemiologic characteristics of invasive pneumococcal diseases (IPD) among a population in a pediatric hospital in Mexico City and analyze mortality-related risk factors, serotype distribution and antibiotic susceptibility related to S.pneumoniae. Material and Methods. We performed a retrospective review of IPD cases at a third level pediatric hospital between 1997-2004. Results. A total of 156 patients were included. The mortality rate was $27.5 \%$ and was associated with six pneumococcal serotypes: I4,6B, 23F, 6A, I9F and 19A. There was no relationship between mortality and antimicrobial susceptibility pattern. A total of $28.2 \%$ of isolates were resistant to penicillin and $24.6 \%$ were resistant to cefotaxime. A statistically significant relationship was observed between mortality and previous underlying disease $(\mathrm{Cl} 95 \%$; 2.5 - I 8.3; $p<0.05)$ using a multivariate logistic regression model. Conclusions. Our outcomes show that IPD mortality in our population is closely related to underlying disease and to six serotypes, five of which are included in the 7-valent pneumococcal conjugate vaccine.
\end{abstract}

Key words: pneumococcal infections; epidemiology; microbial sensitivity tests; Mexico
Gómez-Barreto D, Espinosa-Monteros LE, López-Enríquez C, Jiménez-Rojas V, Rodríguez-Suárez R. Enfermedad neumocócica invasora en un hospital pediátrico de tercer nivel en la Ciudad de México: características epidemiológicas y factores de riesgo asociados con mortalidad. Salud Publica Mex 2010;52:391-397.

\section{Resumen}

Objetivo. Conocer la epidemiología de la enfermedad neumocócica invasora (ENI) en un hospital pediátrico y analizar los factores de riesgo relacionados con la mortalidad, la distribución de serotipos y el patrón de susceptibilidad de S. pneumoniae. Material y métodos. Revisión retrospectiva de los casos de ENI en un hospital pediátrico de tercer nivel, entre 1997 y 2004. Resultados. En 156 pacientes la mortalidad fue de $27.5 \%$. Los serotipos de neumococo más frecuentemente relacionados con la mortalidad fueron: 14 , 6B, 23F, 6A, I9F y I9A; no hubo relación de mortalidad con la resistencia a antibióticos. El $28.2 \%$ mostró resistencia a penicilina y $24.6 \%$ a cefotaxima.A través del modelo multivariado, se encontró una relación estadísticamente significativa entre la mortalidad y enfermedad previa (IC 95\%; 2.5-18.3; $p<0.05)$. Conclusiones. La mortalidad asociada a la ENI tuvo relación significativa con antecedente de una enfermedad previa y con seis serotipos, cinco incluidos en la vacuna neumocócica conjugada 7-valente.

Palabras clave: infecciones neumocócicas; epidemiología; pruebas de sensibilidad microbiana; México

(I) Hospital Infantil de México Federico Gómez. México DF, México.

(2) Hospital General Dr. Manuel Gea González. México DF, México.

(3) Hospital Español. México DF, México.

(4) Secretaría de Salud. México DF, México.

Received on: May 12,2010 - Accepted on: June 24, 2010

Address reprint requests to: Dr. Demóstenes Gómez Barreto. Hospital Infantil de México Federico Gómez.

Dr. Márquez 162, Col Doctores. 06720 México DF.

E-mail: dgbarreto30@yahoo.com.mx 
P neumococcal-related infections are a significant cause of morbidity and mortality worldwide. ${ }^{1,2}$ Invasive pneumococcal disease (IPD) has a fatality rate between $2.6 \%$ and $6 \%$ in industrialized countries, ${ }^{3}$ and some studies have described the relationship between mortality risk and host factors (age, depleted immune response, chronic disease and infection site). ${ }^{4-6}$ There is also evidence of an association between pneumococcal serotype and risk of serious and fatal disease. ${ }^{7}$

The annual incidence of the disease in industrialized countries where the 7-valent pneumococcal conjugate vaccine (PCV7) is not universally administered is 160 cases per 100000 inhabitants. ${ }^{1}$ Attack rates are 1-2 per 1000 children for the invasive form of pneumococcal disease, with Streptococcus pneumoniae isolated in children less than 2 years of age. ${ }^{1}$ Nevertheless, the current Streptococcus pneumoniae disease attack rate, both invasive and non-invasive, is underestimated because the real load is determined by pneumonia and otitis media, conditions that are not regularly reported ${ }^{8,9}$ In addition, many invasive infections caused by pneumococcus are bacteremias with no apparent infectious focus.

A study of 728 children (2000-2005) describes the pneumococcal serotypes in IPD in 10 Latin American countries (SIREVA study), including Mexico. This study does not, however, make any references to risk factors associated with death or with IPD in children. ${ }^{10}$

The current IPD load is considered a worldwide public health problem since every year 1.2 million children die from this disease, surpassing the number of deaths caused by any other infectious diseases that are preventable through vaccination. Thus, this is a very significant problem for developing countries. In addition, in industrialized countries such as the United States, pneumococcus caused 40000 deaths each year (mainly adults) before universal vaccination was implemented..$^{1,9,11}$

Another relevant global aspect of epidemiological pneumococcus is that in the past 20 years there has been a decrease in susceptibility to penicillin and other antibiotics $^{10}$ resulting in strategic changes in IPD therapeutics leading to increased morbidity and treatment costs. ${ }^{12-14}$ At present, the best way to control IPD -especially for the pediatric population under 2 years of age and for patients with IPD factors-is the application of the PCV7. This is the only vaccine approved by the Food and Drug Administration (FDA) and has shown to be especially effective for IPD (97\%). ${ }^{15}$ Furthermore, additional beneficial effects have been reported, such as herd immunity and a decreased resistance to penicillin and other antibiotics for serotypes included in the vaccine, as well as for the new serotypes (post-vaccine) associated with IPD. ${ }^{16-19}$
This study was performed in a third-level pediatric hospital in Mexico City to determine the conditions associated with IPD, pneumococcal serotypes, antibiotics susceptibility and host risk factors and their association with morbidity and mortality rates. In addition, we aimed to identify the potential impact of conjugate vaccines in order to achieve, as reported in other countries, decreased IPD-related mortality and increased susceptibility of pneumococcus to different antibiotics. ${ }^{19}$

\section{Materials and Methods}

We performed a retrospective review of patients who had S.pneumoniae isolated in a sterile site [cerebrospinal fluid (CSF), blood, pleural fluid, peritoneal fluid, synovial secretion] from January 1997 to August 2004 and who had no history of vaccination with PCV7, since this vaccine has only been applied since 2007 as part of nationwide vaccinations in Mexico. The protocol was submitted to the Institutional Research Committee and approval of this clinical study was obtained. The following variables were reviewed: age in months, gender, attendance in daycare centers, nutritional status, previous health status, use of beta-lactam antimicrobials within 30 days of condition onset, and isolation. We analyzed the relationship between age (younger than 24 months), previous health status, S. pneumoniae serotype, antimicrobial susceptibility and beta-lactam antimicrobials mortality rate. The mortality risk was the most important variable in the study.

\section{Identification and susceptibility test}

Pneumococcus was identified by standardized microbiological methods. Penicillin and cefotaxime susceptibility tests were conducted with the microdilution method as established by the Clinical and Laboratory Standards Institute (CLSI before NCCLS). ${ }^{20}$ The serotyping was conducted using Quellung reaction with serum produced by the Statens Institute (Copenhagen, Denmark); the serogroup and serotype were identified according to Danish nomenclature. ${ }^{21}$ All these procedures were conducted in a specialized reference laboratory for streptococcal disease in the Hospital Infantil de México Federico Gomez, in Mexico City.

\section{Clinical definitions}

The clinical syndromes found in patients from whom $S$. pneumoniae was isolated from a sterile site (specified as inclusion criteria) were defined as invasive pneumococcal disease according to international standards. ${ }^{22}$ 
Pneumococcal meningitis: any patient with neurologic findings compatible with meningitis and pneumococcal growth in the CSF culture associated with cytochemical abnormalities (low glucose, elevated proteins and increased cellularity with polymorphonuclear predominance). Pneumococcal bacteremia: a positive blood culture in a patient with fever and no localized infectious source. Pneumonia with effusion: a patient with clinical and/or radiological data compatible with pneumonia and/or effusion and positive blood and/or pleural fluid cultures. Pneumococcal peritonitis: isolation of S. pneumoniae in the peritoneal fluid or in blood from a patient with acute peritonitis and / or compatible cytochemical abnormalities of the peritoneal fluid. Pneumococcal septic arthritis: a patient with arthritis and pneumococcus isolated from synovial fluid.

\section{Statistical method}

A retrospective review was conducted to assess risk factors associated with mortality. All values are expressed as mean and percentage. Differences between groups were estimated using the $X^{2}$ test. Progression to death was estimated with a multivariate logistic regression model, considering $p<0.05$ a statistically significant difference. The logistic regression analysis was performed with the SPSS 12 program.

\section{Results}

\section{Demographic characteristics}

From January 1997 to August 2004, 156 IPD cases were identified in 156 patients with the following ages: $41 \%$ were under 2 years of age and $59 \%$ were over 2 years of age, $1.8 \%$ were under two months of age, and median age was 24 months with a mean of 45.7 months (range: 1 -170 months).

\section{Daycare center attendance}

Ten percent had a history of daycare attendance and $29.4 \%$ of those were previously healthy patients.

\section{Health status}

A total of $30.7 \%$ of the patients were previously healthy and $69.3 \%$ had an underlying disease. IPD distribution among these can be observed in Figure 1.

The more frequent IPD syndromes in healthy subjects $(30.1 \%)$ were meningitis $(16 / 156 ; 10.3 \%)$ and complicated pneumonia $(15 / 156 ; 9.6 \%)$, followed by bacteremia without apparent infectious source $(13 / 156$;

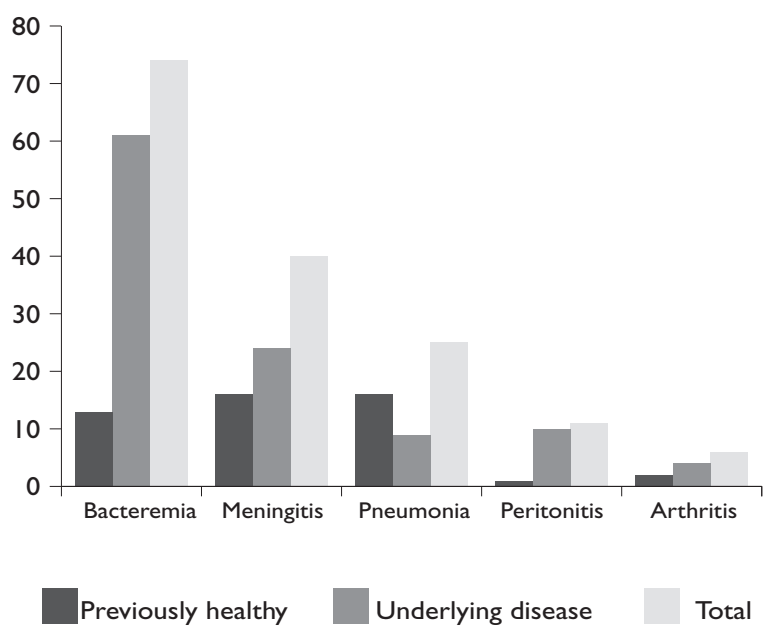

Hospital Infantil de México Federico Gómez, 1997-2004. Mexico City

Figure I. Previous health status in Patients With inVaSIVE PNEUMOCOCCAL DISEASE

8.3\%). Two patients experienced peritonitis $(1.3 \%)$ and one patient had arthritis $(0.6 \%)$. Among patients who had underlying disease $(69.9 \%)$, the most frequent IPD syndrome was bacteremia without apparent infectious source $(37.8 \%)$, followed by meningitis $(15.4 \%)$, pneumonia $(7.7 \%)$, peritonitis $(5.8 \%)$ and arthritis $(3.2 \%)$.

We observed that meningitis and peritonitis were more significant for the group with underlying disease than for the healthy patients $(p>0.05)$ (Table 1$)$.

In our total sample of patients, no statistically significant relationship was found between previous attendance in nurseries or daycare centers and IPD risk; this was also true for previous nutritional status.

Nutritional status at the moment of IPD diagnosis was $45 \%$ eutrophic and $55 \%$ malnutrition, $13.7 \%$ of which had third degree malnutrition according to the Gómez rating scale. ${ }^{23}$ Of the previously healthy patients, $84.6 \%$ had no type of malnutrition, $13.5 \%$ of patients experienced first degree malnutrition and $1.9 \%$ second degree malnutrition.

\section{Previous antibiotic therapy}

A total of $53.6 \%$ of the children included in the study had received beta-lactam antibiotics (cephalothin, cephalexin, cefuroxime, ceftriaxone, amoxicillin and/ or amoxicillin/clavulanate). A statistically significant relationship was found between the history of previous use of beta-lactam antibiotics and penicillin and third 
Table I

ISOLATION OF STREPTOCOCCUS PNEUMONIAE SITE AND ITS RELATION WITH PREVIOUS HEALTH STATUS

\begin{tabular}{|c|c|c|c|c|c|c|}
\hline \multirow[b]{3}{*}{ Bacteremia } & \multirow{3}{*}{$\begin{array}{l}\text { Previously healthy } \\
\qquad \begin{array}{c}\text { (PH) } \\
13\end{array}\end{array}$} & \multirow{3}{*}{$\begin{array}{l}\text { Underlying disease } \\
\qquad \begin{array}{c}\text { (UD) } \\
6 \mathrm{I}\end{array}\end{array}$} & \multicolumn{2}{|c|}{ Mortality } & \multicolumn{2}{|c|}{ Total } \\
\hline & & & \multirow[t]{2}{*}{$\mathrm{PH}$} & \multirow{2}{*}{$\begin{array}{l}\text { UD } \\
22\end{array}$} & \multicolumn{2}{|c|}{ Cases Deaths } \\
\hline & & & & & 74 & 23 \\
\hline Meningitis & 16 & 24 & 6 & 9 & 40 & 15 \\
\hline Pneumonia & 16 & 9 & $\mathrm{I}$ & 3 & 25 & 4 \\
\hline Peritonitis & 1 & 10 & 1 & 0 & 11 & 1 \\
\hline Arthritis & 2 & 4 & 0 & 0 & 6 & 0 \\
\hline Total & 48 & 108 & 9 & 34 & 156 & 43 \\
\hline
\end{tabular}

generation cephalosporin resistance (OR 5.4; 95\% CI 2.4-16.1; $\mathrm{p}<0.05)$.

\section{Isolation site and relation to age}

The distribution was: occult bacteremia $74 / 156(47.5 \%)$, mean age 41.1 months; meningitis $40 / 156(25.6 \%)$, mean age 34.1 months; pneumonia $25 / 156(16 \%)$, mean age 43.7 months; peritonitis $11 / 156(7.1 \%)$, mean age 92 months; arthritis 6/156 (3.8\%), mean age 42.6 months (Table 1).

A statistically significant relationship was found between meningitis and underlying disease $(p>0.05)$, and we therefore believe that this is why we found so many meningitis cases among children who were over 2 years of age.

\section{Isolated serotypes}

The distribution for the nine most frequent serotypes, in decreasing order, was: $23 \mathrm{~F}, 19.5 \%$; $6 \mathrm{~B}, 10.4 \%$; $19 \mathrm{~F}, 9.5 \%$; 6A and $14,8.5 \%$ each; $19 \mathrm{~A}$ and $9 \mathrm{~V}, 5.5 \%$ each; and finally 5 and 11D, $4.9 \%$ each.

The five most frequently isolated serotypes in previously healthy children were: $6 \mathrm{~B}, 5.8 \%$; $14,5.1 \% ; 5,3.2 \%$; 19F, 3.2\% and 4, 2.6\%. In children with previous underlying conditions they were: $23 \mathrm{~F}, 18.3 \%$; $6 \mathrm{~A}, 8.5 \%$; $19 \mathrm{~F}, 6.5 \%$; $6 \mathrm{~B}, 4.9 \%$; and $14,3.7 \%$. We found a statistically significant relationship $(p<0.05)$ between the IPD serotype 23F and underlying disease and previously healthy patients. No statistically significant relationship was found with health status for the remaining serotypes.

Dispersion variables showed a statistically significant relationship $(p<0.05)$ among different serotypes and the type of disease caused.

\section{Susceptibility}

Out of 40 S. pneumoniae isolated in CSF (meningitis), $61 \%$ were penicillin-susceptible and $39 \%$ were penicillin resistant. In the case of cefotaxime, $65.4 \%$ susceptible isolates were found and $34.6 \%$ were resistant (3.8\% with intermediate susceptibility and $30.8 \%$ resistant). The most frequent serotypes that were penicillin resistant, in decreasing order, were: $14(28 \%) 19 \mathrm{~F}, 6 \mathrm{~B}$ and $23 \mathrm{~F}$ (16\% each), 15C (8\%) and 6B (14.2\%). Cefotaxime nonsusceptible serotypes were: $23 \mathrm{~F}(33.3 \%), 19 \mathrm{~F}, 14$ and $6 \mathrm{~B}$ (22.2\%, each).

Out of 116 non-meningitis isolates of S. pneumoniae, $83.5 \%$ were penicillin-susceptible and $16.5 \%$ were penicillin resistant (12.2\% with intermediate susceptibility and $4.3 \%$ were highly resistant). The most frequent serotypes that were penicillin resistant, in decreasing order, were: $6 \mathrm{~B}(31.6 \%), 14,23 \mathrm{~F}$ and $19 \mathrm{~F}(15.8 \%$ each), $9 \mathrm{~V}(10.4 \%), 3$ and 5 (5.3\% each).

In the case of cefotaxime, 90 susceptible isolates were found $(77.6 \%)$ and $26(22.4 \%)$ were resistant $(71.8 \%$ with intermediate susceptibility and $28.2 \%$ resistant). Cefotaxime non-susceptible serotypes were: $23 \mathrm{~F}(33.4 \%)$, 19F $(23.1 \%), 14(15.3 \%) 6 \mathrm{~B}(10.3 \%), 9 \mathrm{~V}(7.7 \%), 19 \mathrm{~A}(7.7 \%)$ and $18 \mathrm{~A}(2.6 \%)$.

A total of 61 isolates of $S$. pneumoniae in patients with a history of beta-lactam therapy were resistant as follows: $51(31.1 \%)$ to penicillin, $17(10.4 \%)$ to cefotaxime and $11(6.7 \%)$ to other beta-lactam.

A statistically significant relationship was found between serotypes 23F, 19F, 14 and $6 \mathrm{~B}$ and non-susceptibility to penicillin and cefotaxime (Figure 2). No statistically significant relationship was found in the remaining serotypes with regard to non-susceptibility to these antimicrobial agents. 


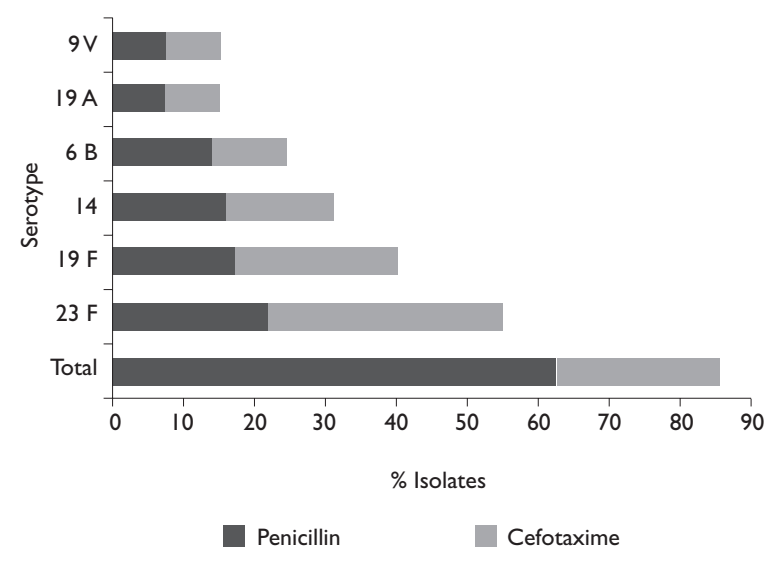

Hospital Infantil de México Federico Gómez, 1997-2004. Mexico City

Figure 2. Percent of Penicillin ANd Cefotaxime ResistanCE RELATED to StREPTOCCUS PNEUMONIAE SEROTYPES

\section{Mortality}

Overall mortality was $27.5 \%$ (43/156); $81.4 \%$ had an underlying disease and $18.6 \%$ was previously healthy. A statistically significant relationship was found between mortality and underlying disease (OR 5.4; 95\% CI 2.518.3; $p<0.05$ ) (Table II). Patients with IPD who correlated with a greater mortality risk had bacteremia and meningitis (OR 2.3; 95\% CI 0.9 -6) (Table III). Of the isolates from patients who died, $40.8 \%$ were non-penicillin-susceptible and $18.6 \%$ were non-cefotaxime-susceptible. No statistically significant relationship was found between antimicrobial susceptibility and mortality.

Serotypes more highly related to mortality were: $14(16.7 \%), 6 \mathrm{~B}(16.7 \%), 23 \mathrm{~F}(14.6 \%), 6 \mathrm{~A}(12.5 \%), 19 \mathrm{~F}(6.3 \%)$, $19 \mathrm{~A}(6.3 \%), 9 \mathrm{~V}(4.1 \%), 18 \mathrm{C}(4.1 \%)$ and $10 \mathrm{~A}(4.1 \%)(p<$ 0.005).
Table II

RISK FACTORS ASSOCIATED WITH MORTALITY IN PATIENTS WITH IPD

\begin{tabular}{lll}
\multicolumn{1}{c}{ Factor } & OR $(95 \% \mathrm{Cl})$ & \multicolumn{1}{c}{$P$} \\
Age (under 24 months) & $0.8(0.2-6.8)$ & 0.073 (NS) \\
\hline Gender (male) & $0.5(0.1-2,0)$ & $0.16(\mathrm{NS})$ \\
\hline Meningitis and/or bacteremia diagnosis & $2.3(0.9-6.1)$ & 0.0003 \\
\hline Previous beta-lactam & $5.9(2.2-15.0)$ & 0.004 \\
\hline Previous underlying disease & $5.4(2.5(18.3)$ & 0.0001 \\
\hline Decreased penicillin susceptibility & $0.9(0.2-4.8)$ & 0.19 (NS)
\end{tabular}

Hospital Infantil de México Federico Gómez, 1997-2004. Mexico City

\section{Discussion}

The age distribution in our study was different than that reported by other authors, ${ }^{24-26}$ and primarily corresponded to ages over 24 months. This is related to particular characteristics of the population involved, since $68.9 \%$ had an underlying disease in contrast with other series for which this figure was lower $(23 \%$ and $29 \%) .{ }^{27}$ Importantly, most previously healthy children in our study who had IPD were under 2 years of age, as was found in other studies. ${ }^{24,25,27}$ We also found that meningitis and bacteremia were related with a high mortality rate, a fact that has been reported in other studies. ${ }^{7,25}$

In the present study, we analyzed 156 S. pneumoniae isolates in 6 years, we found 27 serotypes, $59 \%$ are including in PCV7, 68.6\% in PCV10, and 81.4\% in PCV13.

The most frequent serotypes isolated in this group were: $23 \mathrm{~F}(20.5 \%), 6 \mathrm{~A}(10.9 \%), 19 \mathrm{~F}(10.3 \%), 6 \mathrm{~B}(9 \%), 14$ $(9 \%), 9 \mathrm{~V}(5.6 \%), 19 \mathrm{~A}(5.6 \%), 5(5.1 \%)$, and 11D (5.1\%). These results are different than those of the SIREVA study, in which they included 8993 S. pneumoniae sero-

Table III

AGE AND MORTALITY RISK FOR PATIENTS WITH IPD

Variable
Total patients
$(n=156)$

Living patients $n(\%)$ $(n=1 / 3)$ Dead patients $n(\%)$
$(n=43)$ $p$ value

(Cl)

Age (months)

\begin{tabular}{lllll}
$0-23 / 12$ & 64 & 48 & 16 & \\
\hline $24-59 / 12$ & 45 & 34 & 11 & 0.073 (NS) \\
\hline$\geq 60 / 12$ & 47 & 31 & 16 &
\end{tabular}

Hospital Infantil de México Federico Gómez, 1997-2004. Mexico City 
type isolates from 10 Latin American countries (including Mexico).

Compared to the Mexican SIREVA study during a similar period (2000-2005), ${ }^{10}$ we found that only $41 \%$ of our children was younger than 2 years of age, as opposed to $77.8 \%$. Said difference may be related to the kind of patients in the study (our patients were from only one Mexico City reference hospital and 68.9\% had underlying disease). Nevertheless, we must be cautious when trying to make a comparison with our results, since geographical contrasts can result in some variations among the different serotypes. Whereas we present data from 156 cases of S. pneumoniae isolated from invasive pneumococcal disease in a single concentration hospital in Mexico City, the SIREVA data is based on 728 cases from different cities in Mexico.

An interesting fact is that in the SIREVA study, serotype 14 was the most frequent, unlike our data in which it ranked fifth (9\%). On the other hand, we identified serotype $23 \mathrm{~F}$ as one of the most frequent $(19.5 \%)$, and serotype $19 \mathrm{~F}$ was more frequent than in the SIREVA study (9.5\% vs. 5-6.8\%). Finally, serotypes $6 \mathrm{~A}$ and $6 \mathrm{~B}$ were similar in both studies. Our results are similar with world reports in which serotypes 23F, 19F, 14 and $6 \mathrm{~B}$ are most prevalent in children with IPD. ${ }^{28}$

In African and Latin American countries, serotypes 1 and 5 are most frequently found in children younger than 5 years of age. ${ }^{25,29}$ In this study, the mortality was very high (28\%) as compared with the series from industrialized countries such as Canada, where mortality is 2\%, the United States (2.16\%) and Europe (1\%).3,30 Nevertheless, patients with IPD in said series ${ }^{23,27,28,31}$ were previously healthy, in contrast with ours where $68.9 \%$ had a debilitating underlying disease, which is a mortality risk factor also shown in a study conducted in the US, where mortality was higher in children with previous debilitating disease. ${ }^{32}$ In industrialized countries where PCV7 is regularly applied, mortality figures for IPD in children with infection secondary to the human immunodeficiency virus (HIV) and cancer were lower than in our population. ${ }^{23,32,33}$

In our study, underlying disease was a significant risk factor associated with mortality, where previous debilitating disease has an OR of 5.4 as compared to previously healthy cases (95\% CI; $p<0.05)$. Our mortality data are comparable to those reported for Latin America. ${ }^{26,28,34}$

Regarding gender, in this study, similar to other studies, $8,9,28,33$ we found more male cases (1:1-5), but we didn't find statistic association between genders from both age groups and the mortality risk.
Since most $(62.5 \%)$ mortality-related serotypes are included in the serotypes contained in the PCV7, they could be prevented by the vaccination.

Of the isolated serotypes in patients who died due to IPD, 62.5\% are included in PCV7, 66.7\% are included in the 10-valent pneumococcal conjugate vaccine (PCV10), and $85.4 \%$ in the 13-valent pneumococal conjugate vaccine (PCV13).

When analyzed separately in terms of the potential protection provided by PCV7 in different clinical settings, the study showed that bacteremia would be $65.7 \%$, meningitis $73.2 \%$ and complicated pneumonia $40 \%$. Since $25 \%$ of the isolated serotypes in this clinical entity were 1 and 5 , we did not compare these results with SIREVA results because they analyzed only pneumonia and meningitis, and did not analyze other IPD. ${ }^{10}$

With the new pneumococcal conjugate vaccines (PCV10 and PCV13), and particularly in the case of complicated pneumonia, potential protection increases from $40 \%$ with the application of PCV7 to $88 \%$ with PCV13; these results are similar to those reported by the SIREVA study. ${ }^{10}$

Out of 156 S. pneumoniae serotypes isolated from IPD in our population, 59\% are included in the PCV7, more than that stated in other regional reports. ${ }^{10}$

Regarding antibiotic susceptibility, $74.2 \%$ of the penicillin resistant serotypes are included in PCV7, $77.1 \%$ would be covered by PCV10 and $93.4 \%$ by PCV13. Of the cefotaxime resistant serotypes, $71.8 \%$ are covered by PCV7, 78.9\% by the experimental PCV10 and 91.7\% by the experimental PCV13.

\section{Conclusions}

The results we are reporting are based on experience in a third level pediatric hospital, thus they may not reflect IPD epidemiological behavior throughout the country or its relationship with prevalent serotypes. It is therefore critical to create surveillance programs to generate nationwide data before the universal application of conjugate vaccines, which are already in process in Mexico.

Invasive pneumococcal disease in Mexican children in a third level hospital is a significant cause of morbidity and mortality since it is a sizeable disease among children with previous underlying disease. The key to the control of this disease is the introduction of conjugate vaccines that are effective in children under 2 years of age, those with the greatest IPD incidence. In Mexico, the recent universal introduction of PCV7 addresses this problem. 


\section{Declaration of conflicts of interest}

We declare that we have no conflicts of interest.

\section{References}

I. Centers of Disease Control and Prevention. Prevention of pneumococcal disease. Recommendations of the Advisory Committee on Immunization Practice (ACIP). MMWR Morb Mortal Wkly Rep 1997;46 (RR-8):I-24.

2. Centers of Disease Control and Prevention. Preventing pneumococcal disease among infants and young children: recommendations of the Advisory Committee on Inmunization Practices (ACIP). MMWR 2000;49 (RR-09): I-35.

3. Syriopoulou V, Daikos GL, Soulis K, et al. Epidemiology of invasive childhood pneumococcal infections in Greece.Acta Pediatr Suppl 2000;89:30-34

4. Bedford H, de Louvois J, Halket S, Peckham C, Hurley R, Harvey D. Meningitis in infancy in England and Wales: followup at age 5 years. BMJ 200I;323:533-536.

5. Yu VL, Chiou CC, Feldman C, Ortqvist A, Rello J, Morris AJ, et al. An international prospective study of pneumococcal bacteremia, correlation with in vitro resistance, antibiotics administered, and clinical outcome.

Clin Infect Dis 2003;37:230-237.

6. Levine OS, Farley M, Harrison LH, Lefkowitz L, McGeer A, Schuchat A. Risk factors for invasive pneumococcal disease in children: a populationbased case-control study in North America. Pediatrics 1999; I03:E28. 7. Rückinger $S$, von Kries R, Siedler A, van der Linden M.Association of serotype of Streptococcus pneumoniae with risk of severe and fatal outcome. Pediatr Infect Dis J 2009;28: I I8- 122.

8. Turner RB, Lande AE, Chase P, Hilton N,Weinberg D. Pneumonia in Pediatrics outpatients: cause and clinical manifestations.J Pediatr 1987; III:194-200.

9. Lee GM, Harper MB. Risk of bacteremia for febrile young children in the post-Haemophilus influenzae type b era.Arch Pediatr Adolesc Med 1998; 152:624-628.

10. Castañeda E,Agudelo IC, Regueira M, Corso A, de Cueto Brandileone MC, et al. Laboratory-based surveillance of Streptococcus pneumoniae invasive disease in children in 10 Latin American countries: a SIREVA II project, 2000-2005. Pediatr Infec Dis I 2009;28;e265-e270.

II. Center for Disease Control and Prevention (CDC). Progress in introduction of pneumococcal conjugate vaccine worldwide, 2000-2008. MMWR Morb Mortal Wkly Rep 2008;57(42): I |48-I I5I.

12. Butler JC, Hofmann J, Cetron MS, Elliott JA, Facklam RR, Breiman RF. The continued emergence of drug-resistant Streptococcus pneumoniae in the United States:An update from the Centers for Disease Control and Prevention's Pneumococcal Sentinel Surveillance System.J Infect Dis 1996; 174(5):986-993.

13. Appelbaum PC. Resistance among Streptococcus pneumoniae: implications for drug selection. Clin Infect Dis 2002;34:1613-1620. 14. Hortal M, Lovgren M, de la Hoz F,Agudelo Cl, Brandileone MC, Camou $T$ et al.Antibiotic resistance in Streptococcus pneumoniae in six Latin American countries: 1993-1999. Surveillance Microb Drug Resist 200 I;7: $391-401$.

I5. Eskola J, Black S, Shinefield H. Pneumococcal conjugated vaccines. In Plotkin SA, Orstein WA, eds. Vaccine $4^{\text {th }}$ ed Philadelphia WB Saunders. 2004: 539-524.

16. Black S, Shinefield H, Fireman B, Lewis E, Ray P, Hansen JR., et al. Efficacy, safety and immunogenicity of heptavalent pneumococcal conjugate vaccine in children. Northern Californi Kaiser Permanente Vaccine Study Center Group. Pediatr Infect Dis J 2000; 19:187- 195.
I7. Eskola J, Kilpi T, Palmu A, Jokinen J, Haapakoski J, Herva E., et al. Efficacy of a pneumococcal conjugate vaccine against acute otitis media. N Engl Med 200I;344:403-409.

18. Whitney CG, Farley MM, Hadler J, Harrison LH, Bennett NM, Lynfield $R$, et al. Decline in invasive pneumococcal disease after the introduction of protein- polysacharide conjugate vaccine. N Engl J Med 2003;348: 1737-1746.

19. Kyaw MH, Lynfield R, Schaffner W, Craig AS, Hadler J, Reingold A. et al. Effect of introduction of the pneumoccocal conjugate vaccine on drugresistant Streptococcus pneumoniae. N Engl ] Med 2006;354: I 455- I 463. 20. Clinical and Laboratory Standards Institute. Performance Standards for Antimicrobial Susceptibility Testing: Eighteenth Informational Supplement MI00-S08. Pennsylvania: CLSI, 2008;28(I).

21.Austrian R.The quellung reaction, a neglected microbiologic technique. Mt Sinai J Med 1976;43:699-709.

22. Dagan R, Greenberg D, Jacobs M, Philips B. Pneumococcal infections. In Feigin, Cherry, Demmler-Harrison, Kaplan, eds. Textbook of pediatric infectious diseases. 6th ed. Philadelphia:WB Saunders, 2009: I 288-I342. 23. Palacios T, Gamez J, Flores H. Desnutrición energético proteica en: Introducción a la pediatría. Chapter 14. 6th ed. Mexico: Méndez Editores, 1991: |31-142

24. Scheifele D, Halperin S, Pelletier L, Talbot J. Invasive pneumococcal infections in Canadian children, 1991-1998: implications for new vaccination strategies. Canadian Paediatric Society/Laboratory, Centre for Disease Control Immunization Monitoring Program, Active (IMPACT). Clin Infect Dis 2000;31:54-64.

25. Jacobs NM, Lerdkachornsuk S, Metzger WI. Pneumococcal bacteremia in infants and childreen: a ten year experience of the Cook County Hospital with special reference to the pneumococcal serotypes isolated. Pediatrics 1979; 64(3):296-300.

26. Ulloa-Gutierrez R,Avila-Aguero ML, Herrera ML, Herrera JF,Arguedas A. Invasive pneumococcal disease in Costa Rican children: a seven year survey. Pediatr Infect Dis J 2003;22:1069-1074.

27. Davison M, Parkinson AJ, Bulkow LR, Fitzgerald MA, Peters HV, Parks DJ.The epidemiology of invasive pneumococcal disease in Alaska, 1986 1990: ethnic differences and opportunities for prevention.J Infect Dis 1994; 170: 368-376.

28. Dinleyici EC,Yargic ZA. Current knowledge regarding the investigational I3-valent pneumococcal conjugate vaccine. Expert Rev Vaccine 2009;8:977-986.

29. Kertesz DA, DiFabio JL, de Cunto Brandileone MC, Castañeda E, Echániz-Avilez G, Heitmann I, et al. Invasive Streptococcus pneumoniae infection in Latin American children: results of the Pan American Health Organization Surveillance Study. Clin Infect Dis 1998;26:1355-136I. 30. Levine MM, Lagos R, Levine OS, Heitmann I, Enriquez N, Pinto ME, et al. Epidemiology of invasive pneumococcal infections in infants and young children in Metropolitan Santiago, Chile, a newly industrializing country. Pediatr Infect Dis J 1998;17(4):287-293.

31. Pneumococcal regional serotypes distribution for pneumococcal AMC TPP. [Available at: www.Vaccineaamc.org/filesTTP_codebook.pdf] 32. Kaplan SL, Mason EO, Wald E, Tan TQ, Schutze GE, Bradley JS, et al. Six year multicenter surveillance of invasive pneumococcal infection in children. Pediatr Infect Dis J 2002;2I (2):I4I-I47.

33. Haddy RI, Perry K, Chacko CE, Helton WB, Bowling MG, Looney $\mathrm{SW}$ et al. Comparison of incidence of invasive Streptococcus pneumoniae disease among children before and after introduction of conjugated pneumococcal vaccine. Pediatr Infect Dis J 2005;24(4):320-323. 34. Shapiro ED, Austrian R. Serotypes responsible for invasive Streptococcus pneumoniae infections among children in Connecticut.J Infect Dis 1994;169:212-2|4 